\title{
Por uma história social dos trabalhadores do mar : questões lançadas às listas de matrículas de tripulações mercantes em Portugal e seus domínios (1807-1808)
}

\author{
Isabella Rocha Ferreira, Jaime Rodrigues, Bárbara Regina Silva Costa, \\ Beatriz Anselmo de Oliveira, Beatriz Bertolli Paulini, Bruna Macedo Pilon, \\ Daniel Gimene Liossi de Sousa, Daniele de Souza Somensari, \\ Fábio Rogério Banin Júnior, Fernanda Dias Neves, Giovanna Antonelli Santos, \\ Juliana dos Santos Carmona, Juliane Cavalcante, Lais Aparecida Charleaux, \\ Maiara Puk Goes da Silva, Thainá Renata Lopes da Silva, Vitória Ribeiro \\ Universidade Federal de São Paulo (Unifesp)
}

\section{Resumo}

Em uma publicação recente, transcrevemos um conjunto significativo de listas de matrículas da marinha mercante lusa para os anos de 1807 e 1808 , documentação sob a custódia do Arquivo Nacional da Torre do Tombo. Além da transcrição, o artigo apresentou a fonte e suas potencialidades e elencou diversas indagações que, na perspectiva da história social, podem ter respostas ensaiadas a partir da consulta a essas fontes seriais. Nossa intenção, agora, é apresentar algumas reflexões que permitam avançar na resposta a essas mesmas questões, como por quê os estudos sobre a demografia de Portugal no século XVIII estão atrelados ao contingente de trabalhadores marítimos ofertado ao mar no período de nosso recorte, entre outras possibilidades apresentadas pela fonte.

Palavras-chave História social - Trabalhadores do mar - Marinha mercante portuguesa - Século XIX - Listas de matrícula.

\section{Submissão}

23/04/2021 Aprovação

IO/07/202I Publicação

$\mathrm{OI} / \mathrm{IO} / 2 \mathrm{O} 2 \mathrm{I}$ 


\title{
For a Social History of Seafarers: Questions Raised to the Enrolment Lists of Merchant Crews in Portugal and Their Domains (1807-I808)
}

\begin{abstract}
In a recent publication, we have transcribed a significant set, from 1807 and 1808 , of Portuguese merchant navy's enrolment lists, documentation from the National Archives of Torre do Tombo. Besides the transcription, this article presents the source, and its potential, and listed several questions that, from a Social History perspective, may have some responses essayed from these serial sources' consultation. Now, we intend to introduce some reflections that allow us to advance in the answer to these questions, such as, why the studies about Portugal's demography in the I8th century are associated with the contingent of maritime workers in the selected period, among other possibilities cited by the source.
\end{abstract}

Keywords Social History - Sea Workers - Portuguese Merchant Navy - 19th Century Registration Lists.

\section{Por una historia social de la gente de mar: cuestiones planteadas a las listas de registro de las tripulaciones mercantes en Portugal y sus dominios (1807-1808)}

\section{Resumen}

En una publicación reciente, hemos transcrito un importante conjunto de listas de matrícula de la marina mercante portuguesa de los años 1807 y i8o8, documentación bajo la custodia del Archivo Nacional de Torre do Tombo. Además de la transcripción, el artículo presentó la fuente y su potencial y enumeró varias preguntas que, desde la perspectiva de la Historia Social, pueden tener respuestas ensayadas a partir de la consulta con estas fuentes seriadas. Nuestra intención, ahora, es presentar algunas reflexiones que permitan avanzar en la respuesta a estas mismas preguntas, como por ejemplo por qué los estudios sobre la demografía de Portugal en el siglo XVIII están vinculados al contingente de trabajadores marítimos ofrecidos al mar en el período de nuestro recorte, entre otras posibilidades presentadas por la fuente.

Palabras clave Historia social - Trabajadores del mar - Marina mercante portuguesa - Siglo XIX - Listas de registro. 
niciaremos com os aspectos demográficos, desde os mais gerais aos mais específicos, tendo em conta a origem dos embarcados de acordo com as regióes de nascimento. Com que percentual cada região contribuía para a formação dos quadros de homens aptos ao trabalho? Por que algumas regiões se sobressaem? A investigação sobre o percentual com que cada região contribui com contingentes humanos para o trabalho no mar propicia subsídios para estudos históricos sobre o mundo do trabalho marítimo.

O total de matrículas de marinheiros transcritas engloba um universo de 4.628 tripulantes. Por meio da divisão do número total de homens pela província/região de nascimento, excetuando-se aquelas em que tal informação está ilegível ou não consta (307) e outros indivíduos que apareceram registrados mais de uma vez (68), nossa amostragem totalizava 4.253 homens.

Chamou nossa atenção no montante das matrículas a quantidade de tripulantes provenientes de Lisboa e Estremadura (39,29\%), Entre-Douro-e-Minho (29,74\%), Beira (9,57\%) e Ilhas Atlânticas (II,45\%). Somadas, às demais regiões de Portugal, como Alentejo, Algarve e Trás-os-Montes aparecem cada uma com menos de $2 \%$ do total de homens embarcados. A presença de indivíduos do sexo masculino vindos da África (3,33\%), da América Portuguesa (2,86\%), estrangeiros da Europa (1,31\%) e da Ásia $(0,45 \%)$ pode ser objeto de análise acerca de temas como a presença de negros e escravizados nas tripulações mercantes desse período.

Os dados demográficos deixam claro que o contingente de homens provenientes das diferentes regiões históricas de Portugal compreende cerca de $80 \%$ dos identificados nas listas de matrículas. Com base nesses dados, é possível indagarmos a razão pela qual o Reino forneceu a maioria dos trabalhadores marítimos do período. Para responder a tal questão, levamos em conta a formação de Portugal como Estado-nação, tendo em vista, sobretudo, a questão fundiária que, ao produzir uma legião de pessoas que não tinha terra para dela retirar seu sustento e o de seus familiares, contribuiu para tornar o trabalho marítimo uma das poucas alternativas de atividade remunerada para os pobres do Reino.

Se Lisboa e o seu entorno e o Entre-Douro-e-Minho contribuíam com um número equivalente de tripulantes, quando atentamos para os cargos de maior poder a bordo, a situação se mostra diferente. Selecionando os dados sobre os cargos 


\section{REVISTA ANGELUS NOVUS}

hierarquicamente superiores, a área de Lisboa se sobressaía (47,2\% dos capitães; 51,6\% dos pilotos; 16,8\% dos capelães), enquanto o norte (especialmente o Porto e Braga) tinha percentuais menos expressivos (29,6\% dos capitães; $13,9 \%$ dos pilotos; $16,8 \%$ dos capelães), mas ainda assim muito superiores aos das Ilhas atlânticas (6,4\% dos capitães; 3,35\% dos pilotos; $3,2 \%$ dos capelães) e da América portuguesa (3,2\% dos capitães; 8,2\% dos pilotos; $4,8 \%$ dos capelães).

Iniciamos ainda uma análise acerca da proveniência dos tripulantes de acordo com as vilas e freguesias mencionadas nos documentos. Com esse esforço, queremos compreender algumas características dessas tripulações: se havia mais tripulantes vindos de um determinado local; se os tripulantes costumavam levar familiares ou conhecidos para o mundo do trabalho marítimo depois de nele adentrarem (avaliando, para isso, as relações de parentesco existentes, através da identificação de sobrenomes iguais e dos nomes dos pais) ou se um determinado cargo de oficial concentrava seus tripulantes em uma região específica, dentre outras questões. Conseguimos avançar um pouco mais no que se refere à última questão.

Para exemplificar nossas conclusões preliminares, citamos o caso dos capelães. Constatamos que, nos dois anos analisados, eles eram oriundos principalmente das diferentes regiões do arcebispado de Braga. Supomos que isso se deva, primeiramente, ao fato de ser essa a região onde se localiza a sede da arquidiocese, muito importante para a história portuguesa. Em segundo lugar, Braga é uma das mais antigas localidades cristãs da península Ibérica, fundada ainda durante o Império Romano. Considerando esses fatores, percebemos que há tempos existia uma forte tradição católica e de formação do clero no ambiente bracarense e em seu entorno, ajudando a explicar, antes de qualquer outro argumento, que a maioria dos padres viesse dessa área. As conclusões, entretanto, ainda carecem de aprofundamento porque nosso empreendimento se limitou a ordenar e quantificar os locais dos quais vinham os oficiais e não em pesquisar mais profundamente as causas da hegemonia regional.

Em outros cargos de oficiais, como os de capitão e piloto (incluídos aqui os cargos adjacentes a este, como os de sota-piloto, segundo e terceiro piloto e praticante de piloto), o que constatamos é uma superioridade da região de Lisboa em relação à proveniência dos tripulantes. Como já foi dito, os motivos dessa predominância ainda não são claros, mas é preciso lembrar que os navios para os domínios coloniais saíam justamente dessa região, abrangendo a capital do Reino, e provavelmente por isso havia tantos navegantes especializados desta área na Marinha mercante. Acreditamos que as respostas que buscamos ficarão mais evidentes quando tratarmos da análise acerca dos marinheiros, trabalhadores braçais e não especializados, advindos de regiões mais 
diversas. Por ora, não é possível supor se haveria também entre eles o predomínio de Lisboa, mas acreditamos que sua situação era mais diversificada.

Pelas informações levantadas a partir das matrículas transcritas, percebemos que a nacionalidade também merece um olhar atento, bem como a porcentagem de estrangeiros a bordo desses navios. Algumas das questôes que nos guiam na análise desse aspecto da fonte são a quantidade de estrangeiros por navio, quais eram as principais regióes estrangeiras que contribuíam com tripulantes, qual a razão deles estarem em número reduzido e quais cargos ocupavam.

É importante ressaltar que consideramos “estrangeiros” todos aqueles que não eram portugueses nem nascidos na América portuguesa. O quesito "cor” é importante aqui para definir a nacionalidade, e aqueles matriculados como "pretos" ou os naturais de domínios asiáticos foram considerados estrangeiros. Apesar de os nascidos na América portuguesa não serem reinóis, também não podiam ser considerados estrangeiros, já que os dois lados do oceano estavam em constante ligação e as viagens acabavam incluindo muitos "brasileiros", principalmente porque a maior parte das rotas que esses navios faziam tinha como destino o Brasil.

Outra questão a ser observada é a variedade de situações envolvendo pessoas negras que embarcavam nesses navios, por isso contamos as pessoas provenientes do continente africano como estrangeiros. A maioria era de escravos, mas muitos também eram forros ou livres. Notamos que a maior porcentagem de estrangeiros era justamente de africanos, o que implica também considerar a questão da escravidão e dos motivos pelos quais eles apareciam mais nesses navios.

A investigação sobre o percentual de pretos e de escravos na composição das tripulações mercantes nos anos de 1807 e I808 propicia as bases que podem servir de subsídio para estudos históricos sobre o mundo do trabalho marítimo e a escravidão.

Do montante total de matrículas, foram identificados 172 homens pretos e escravos, o que equivale a $3,7 \%$ do total de tripulantes. Tal resultado advém da soma dos 138 homens identificados como pretos e mais 34 homens identificados como escravos, mas que não tiveram a cor especificada. Entendemos que a ausência da cor na documentação pressupõe a crença geral (inclusive entre os escrivães e escreventes) de que, ao especificar a condição social, não era necessário preencher o quesito "cor”, pois ela estaria subentendida pela condição.

Além de todas as dificuldades usuais com a documentação, quando se trata das matrículas de escravos alguns problemas se acentuam, pois não é possível aplicar o método utilizado de amostragem com base na exclusão de tripulantes que embarcam mais de uma vez. Algumas listas possuem matrículas de escravos com nomes repetidos, 


\section{REVISTA ANGELUS NOVUS}

sem outras informações para além da idade e da naturalidade. Por vezes até as idades são muito próximas, mas, ainda assim, não se pode afirmar serem os mesmos homens.

Por causa dessa ausência de dados, optamos por não retirar nenhum nome repetido, mesmo quando este aparecia com a mesma idade e naturalidade e vinculado ao mesmo navio. A lacuna na documentação foi entendida como um dado importante, pois evidencia a diferenciação social e o papel do homem escravizado nessa sociedade, no mar e em terra.

A ideia de que o homem preto era uma propriedade era tão arraigada que, em muitos casos, as matrículas parecem ser o registro de uma mercadoria ou uma bagagem que embarca junto ao senhor. Capitães ou donos de navios embarcavam com seus escravos que tinham o mesmo nome e nenhuma outra informação além dessa. Muitas vezes, esse senhor não precisava sequer decorar os nomes de suas propriedades. Se um oficial do Napoleão I, por exemplo, chamasse por "Antônio", "Joaquim” ou "Manuel”, apareceriam seis escravos para atendê-lo, já que havia dois homens com cada um desses nomes a bordo, na mesma viagem.

Para além do envolvimento de "brasileiros" e africanos (6,19\%), temos aqueles que podem ser considerados claramente estrangeiros, a saber, europeus e asiáticos. Eles totalizaram um número reduzido entre I807 e I8o8 ( $1,76 \%$ do total das equipagens) e, normalmente, exerciam funções de marinheiros. Eram, em sua maioria, espanhóis ( $1,27 \%$ do total da amostragem), mas também de outras nacionalidades: italianos e malteses (o,02\% cada) e asiáticos (o,45\%). Não havia nenhum estrangeiro de língua inglesa ou de áreas de religião protestante, conforme os dados do Gráfico I.

Gráfico I Regióes de proveniência dos tripulantes de navios mercantes portugueses, I807I808

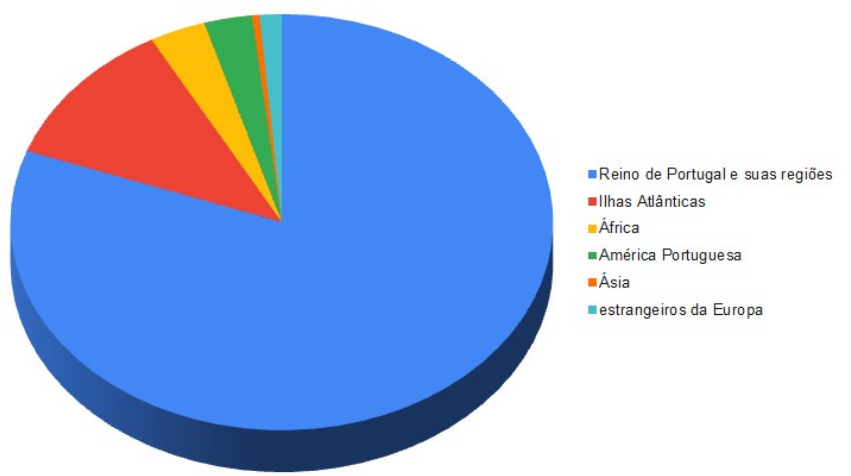

Fonte Arquivos Nacionais/Torre do Tombo, Junta do Comércio, maço 35, ordem 65, caixa II8 transcrito em RODRIGUES, J. et al. "Matrículas de tripulaçôes mercantes em Portugal em I807-I808 como fontes para o trabalho do historiador". Revista de Fontes, v. 7, n. I2, p. I79-455, 2020.

$6 \cdot$ ano XII, n. 17, 202I • ISSN 2179-5487 
Com essas informações, foi possível esboçar algumas conclusões preliminares. Primeiramente, foram poucos os estrangeiros nos navios portugueses nos anos assinalados. Esse fator pode ser explicado por uma tradição da Coroa portuguesa em relação à entrada de estrangeiros no Brasil, que se configurou como um tipo de protecionismo:

Por longos três séculos, do descobrimento (I500) até a famosa abertura dos portos (I808), a receosa coroa portuguesa coibiu - ou pelo menos tentou coibir - com vigor a presença de estrangeiros em território brasileiro, sobretudo depois de 1590 quando passa a legislar neste sentido. ${ }^{1}$

Isso se devia ao fato de que a Coroa portuguesa tentava manter o chamado "exclusivo colonial”, em que as relações comerciais da colônia ficavam restritas à metrópole. Considerando que as autoridades portuguesas não costumavam permitir a entrada de navios estrangeiros no Brasil e muito menos trazer em suas próprias embarcações marinheiros de origem estrangeira, é compreensível que isso não tenha se alterado radicalmente no período compreendido nesta pesquisa, ou seja, o ano que antecedeu a transferência da Corte para o Brasil e o primeiro ano da instalação da nova capital do Reino no Rio de Janeiro.

$\mathrm{Na}$ época colonial, as determinações partidas da Coroa portuguesa contra os estrangeiros eram incisivas e assim se expressaram em uma Carta de Lei de i6os: "hei por bem, que no navio de meus naturais não possa ir pessoa alguma estrangeira, ainda que moradora seja em meus reinos;". Em outro trecho, o mesmo documento declarava qual seria a penalidade para quem o fizesse: "E quaisquer estrangeiros, que em navios seus ou alheios, ou de meus naturais, forem às ditas partes [os territórios coloniais portugueses], contra esta minha lei, além de [...] incorrerem na perda de suas fazendas, incorrerão em pena de morte". ${ }^{2}$ A partir destes trechos, é possível perceber quão séria era a questão, em se tratando de "proteger" os domínios coloniais. Assim, é possível deduzir quão forte era a resistência da administração portuguesa em integrar estrangeiros aos seus navios.

Por conta disso, podemos pensar que esses navios eram locais onde se falava um idioma, com a quase inaudível presença de outros idiomas de origem latina - como o espanhol e o italiano. Rodrigues evidenciou que, quando os navios carregavam tripulantes de diversas nacionalidades, era preciso criar uma linguagem própria, que

I LIMA, C. C. R. de. "Proteger para não perder: as medidas da Coroa portuguesa em relação à entrada de estrangeiros no Brasil colonial”. Revista Espaço Acadêmico, v. II, n. I22, 20II. p. 6I.

2 Carta de Lei de I8 de março de i6os: sobre a navegação dos estrangeiros para as Conquistas apud LIMA, C. C. R. de. "Proteger para não perder: as medidas da Coroa portuguesa em relação à entrada de estrangeiros no Brasil colonial". Revista Espaço Acadêmico, v. II, n. I22, 20II. p. 63. 


\section{REVISTA ANGELUS NOVUS}

fizesse com que os homens se entendessem, apesar das linguagens variadas. Aos estrangeiros "estava praticamente vedada a participação nas equipagens lusas nesse período, o que traz um indicador importante para refletir sobre a cultura desses marinheiros em termos linguísticos e religiosos”. ${ }^{3}$ Esse era um problema praticamente inexistente nos navios portugueses, levando em conta a informação a que temos acesso por meio dessas fontes. Principalmente quando consideramos que pessoas de nacionalidades diversas, como os asiáticos, só apareciam em viagens que tinham por destino ou escala a Ásia. Não podemos afirmar com certeza se eles iam como intérpretes ou agentes comerciais, mas esta é uma hipótese plausível.

Assim também acontecia no caso dos africanos. Em muitas viagens havia africanos embarcando, principalmente na condição de escravos. Mas houve casos de navios em que cerca da metade dos tripulantes era de africanos escravizados, sobretudo em viagens que tinham a costa da África como destino. Uma de nossas hipóteses é de que isso aconteceu justamente porque esses navios tinham por objetivo conseguir novos escravizados traficar e, assim, empregaram muitos intérpretes que pudessem auxiliar na negociação.

Outro tema possível de ser investigado por meio das listas de matrícula é a questão da religiosidade. As listas costumam começar sempre pelo nome do capitão, seguido pelo do capelão - que são, no caso, os representantes do rei e da Igreja. Sabemos o quanto a Igreja era importante em Portugal e o quanto ela foi fundamental nas conquistas e na colonização portuguesa ao redor do mundo. Além de falar uma língua de origem latina, os espanhóis também eram católicos, o que fazia com que esses navios portugueses fossem homogêneos em mais de um sentido. A religiosidade era uma questão importante, e ter pessoas de religião católica a bordo possivelmente evitava eventuais problemas referentes a isso. Ressaltamos que a bibliografia para se estudar a situação dos estrangeiros nos navios mercantes portugueses ainda é reduzida. Trata-se de um campo aberto para pesquisas e para o qual esperamos contribuir.

Durante a transcrição das matrículas, notamos diversas variações na formação dos nomes e sobrenomes dos tripulantes: enquanto uns carregavam nome ou sobrenome do pai, outros traziam o da mãe e outros ainda faziam referências à naturalidade. Havia também os nomes formados por uma intersecção desses casos, como com nome do pai e sobrenome referente ao lugar de nascimento.

Partindo disso, uma das questões que surgiram estava relacionada à viabilidade de trabalhar com genealogias mínimas, para entender um pouco mais a respeito dos

3 RODRIGUES, J. "Marítimo de profissão: as matrículas de marinheiros e a história marítima de Portugal e seus domínios nos séculos XVIII e XIX”. Almanack, n. 2I, 2019. p. 2I.

$8 \cdot$ ano XII, n. I7, 2021 ・ ISSN 2179-5487 
tripulantes e suas famílias. Para lidar com a questão, primeiramente fez-se necessário entender se havia na época alguma padronização na transmissão do nome e sobrenome através das gerações. Elaboramos várias planilhas para abarcar o maior número possível de casos na formação dos nomes e tentar entender como se dava a transmissão desse nome/sobrenome no período e nesse meio social. Tínhamos, então:

- tripulantes com nome e/ou sobrenome referente ou igual ao do pai;

- tripulantes com nome e/ou sobrenome referente ou igual ao da mãe;

- tripulantes com sobrenome referente a uma região;

- tripulantes casados;

- tripulantes com pais incógnitos;

- tripulantes sem menção aos pais no registro;

- tripulantes com cor e/ou condição social mencionada;

- tripulantes que não se encaixam em nenhum dos casos anteriores.

Percebendo as variadas possibilidades, realizamos um breve cotejamento bibliográfico acerca do tema, para que assim pudéssemos entender um pouco mais as razões para tantas possibilidades existentes na época. A partir disso, percebemos a importância do nome no seu sentido social.

Como consequência de uma herança cultural medieval que perdurou até o século XVIII, as pessoas eram conhecidas pelo nome próprio, às vezes seguido do patronímico ou matronímico. Com o crescimento das cidades, tornou-se cada vez mais difícil conhecer toda a comunidade; assim, popularizou-se a necessidade de adicionar um sobrenome aos seus nomes, que podia se referir à profissão exercida, ao local de origem ou às terras que possuía, no caso da nobreza. ${ }^{4}$ Ainda que a prática tenha se popularizado, o segundo nome era adotado de forma relativamente livre:

$\mathrm{Na}$ verdade, não vigorando em Portugal quaisquer normas legais sobre o assunto, o apelido ou conjugação de apelidos mais importantes eram em regra, até ao século XIX, os primeiros que se usavam depois do nome próprio, deixando-se frequentemente cair os restantes. O primeiro apelido era geralmente o paterno, embora se pudessem escolher livremente de entre os usados pelos pais ou pelos quatro avós, sendo frequentes os casos de irmãos que não usavam o mesmo apelido. ${ }^{5}$

Em Portugal, apenas nos anos de I9II e 1928 elaboram-se leis para determinar qual padrão deveria ser seguido.

4 ROWLAND, R. "Práticas de nomeação em Portugal durante a Época Moderna: ensaio de aproximação". Etnográfica, v. I2, n. I, 2008. p. 29.

5 MONTEIRO, N. G. "Os nomes de família em Portugal: uma breve perspectiva histórica”. Etnográfica, v. I2, n. I, 2008. p. 47. 


\section{REVISTA ANGELUS NOVUS}

O primeiro código do registro civil da república, de i8 de Fevereiro de I9II, limitava-se a esclarecer que "nos assentos de nascimento não poderão figurar, em caso algum, os sobrenomes e quaisquer referências honoríficas ou nobiliárquicas do registado, nem títulos ou honras" (art. 244). Porém, o art. 213 do código do registro civil de 1928 continha uma adenda na qual se determinava que "o número de apelidos não deverá ser superior a quatro e serão escolhidos entre os nomes de família dos pais dos registrados, devendo os último ou último ser do pai. ${ }^{6}$

Por intermédio das tabulações que elaboramos, é notório que o maior número de tripulantes $(53,87 \%)$ carregavam o nome e/ou sobrenome do pai, decorrência da matriz patriarcal da sociedade portuguesa. Por outro lado, vale ressaltar que poucos homens assimilavam o sobrenome de sua mãe e, quando o faziam, também traziam o de seu pai: pelas listas de matrícula, esse número alcança $79 \%$ das menções. Assim como a quantidade de tripulantes com o nome referente à mãe é um valor percentual de pouca expressão quando comparado ao número de tripulantes que assimilaram o nome do pai e, principalmente, ao total de matriculados $(6,2 \%)$.

Selecionamos para essas planilhas nomes e sobrenomes, pois percebemos como muitas vezes o filho não tinha o mesmo sobrenome do pai, mas sim seu nome; outras vezes na mesma ordem, e outras ainda em composição com outros nomes, como nos casos abaixo:

a) no navio Princesa do Brasil seguiu Inácio Inácio Joaquim Jorge, natural de Lisboa, 33 anos, filho de Antônio Jorge, solteiro, marinheiro;

b) no navio São Manuel Augusto seguiu Januário Ladislau, natural do Minho, 23 anos, filho de Ladislau Gomes.

Outro caso que chamou nossa atenção foi a adaptação dos nomes entre casais e, em especial, na relação mãe-filho, exemplificada pelos casos abaixo:

a) no navio Viriato seguiu Antônio Querino, natural do Rio Grande, 32 anos, filho de José Querino e de Antônia Querina;

b) no navio Princesa Carlota seguiu Inácio Henriques, natural de Turim, 3I anos, filho de João Batista e de Catarina Henrica.

Havia também casos em que o nome do filho fazia referência ao pai e à mãe simultaneamente, sendo estes, porém, casos de baixa incidência $(4,67 \%)$. É evidente que não se tratava de um costume arraigado e partilhado entre os portugueses, mas esse viria a se fortalecer após o início dos Oitocentos. Segundo Monteiro, “parece datar do século 
XIX o costume de as mulheres adoptarem o apelido do marido, o que [...] não tinha antes expressão significativa, embora se pudesse verificar". ${ }^{7}$

Apesar de certa popularidade em períodos anteriores, ${ }^{8}$ encontramos poucos homens do mar (o,37\%) remetendo seu nome ao local de nascimento ou às regióes nas quais tenham vivido grande parte de sua existência. Mesmo assim, isso se mostrou um mecanismo para atribuir singularidade aos tripulantes e casos como esses, embora pouco registrados nas listas de matrículas, se tornavam alcunhas recorrentes nos processos judiciais, quando esses homens se tornavam autores, réus ou testemunhas.

Com relação aos homens casados, optamos por fazer uma planilha à parte, pois em $84 \%$ dos seus registros só constam os nomes de esposas e não os dos pais, devido às normas para transmissão de herança. Entre aqueles em que constam os nomes dos pais, percebe-se que também há o predomínio do sobrenome paterno (65 casos) se comparado aqueles que carregam sobrenome materno (6 casos). Outro dado que salta aos olhos é a pouco expressiva (17,3\%) transmissão de sobrenomes entre pessoas casadas, demonstrando não se tratar de um hábito instituído na época ou por lei, diferentemente dos tempos posteriores. De acordo com Monteiro, o costume, em Portugal, parece ser do século XIX e, mesmo assim, não se tratava de uma imposição. ${ }^{9}$

Já com relação aos tripulantes filhos de pais incógnitos e/ou pais não mencionados, não foi possível saber como ocorreu a escolha dos nomes e sobrenomes. Faz-se necessário ressaltar que, no caso dos pais incógnitos, ou seja, tripulantes órfãos, tal informação se inscrevia na matrícula; já no segundo caso, a informação simplesmente não era preenchida. $\mathrm{O}$ número de tripulantes sem registro dos nomes dos pais é de 768 homens, os quais representam $16,59 \%$ do total. Acreditamos que a razão disso foi uma certa displicência durante o preenchimento das listas de matrícula.

Porém, tal displicência chega a patamares ainda mais elevados se compararmos as funções exercidas entre si. Os homens que estão nas camas mais baixas da hierarquia de bordo, como marinheiros, moços, mancebos, serventes e escravos, somam 563 homens, representando $73,3 \%$ dos casos com pais não mencionados. A isso se acrescenta o dado que dos 178 tripulantes com cor e/ou condição social mencionada, ou seja, negros e escravos: 167 não tinham os pais mencionados no registro, ou seja, 93,82\%, o que caracterizaria uma tentativa de desumanização decorrente da condição de escravizados.

MONTEIRO, N. G. "Os nomes de família em Portugal: uma breve perspectiva histórica”. Etnográfica, v. I2, n. I, 2008. p. 47.

8 ROWLAND, R. "Práticas de nomeação em Portugal durante a Época Moderna: ensaio de aproximação". Etnográfica, v. I2, n. I, 2008. p. 23. MONTEIRO, N. G., op. cit., p. 47. 
REVISTA ANGELUS NOVUS

Sistematizando os dados para o conjunto da amostragem, temos a representação verificada no Gráfico 2.

Gráfico 2 Menção aos nomes paternos e maternos nas matrículas de equipagens (I807I808)

Tripulantes sem os pais mencionados $=768$

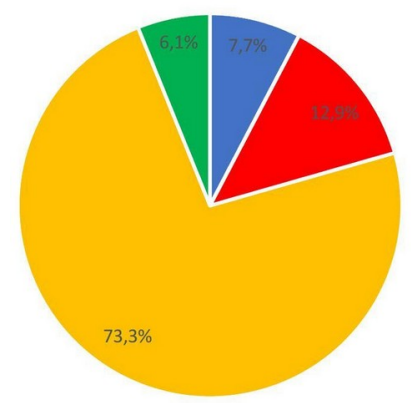

- Capitães e pilotos (59 casos)

- Ofícios diversos (99 casos) exemplos:

contramestre, escrivão, escriturário,

capelão, cirurgião

- Ofícios com trabalho braçal ( 563 casos)

exemplos: marinheiro, servente, mancebo,

moço

- Sem ofício mencionado (47 casos)

Fonte Arquivos Nacionais/Torre do Tombo, Junta do Comércio, maço 35, ordem 65, caixa II8 transcrito em RODRIGUES, J. et al. "Matrículas de tripulações mercantes em Portugal em 1807-1808 como fontes para o trabalho do historiador". Revista de Fontes, v. 7, n. 12, p. I79-455, 2020.

É importante ressaltar que a ausência de dados como nomes dos pais, estado civil, nome da esposa e naturalidade dificultava o reconhecimento dos parentes ascendentes ou colaterais daquele tripulante, criando-se uma barreira para o direito da família de receber a herança deste, em caso de morte. ${ }^{\text {Io }}$ Ao passo que muitos marinheiros não possuem essas informações sobre parentesco próximo registradas, tripulantes com cargos considerados mais altos na hierarquia do navio tem no registro títulos de alguma fidalguia antecedendo os nomes de esposas e pais. Como exemplo, mencionamos o caso do piloto do Conceição e Esperança, Francisco Pereira Pinto Rios, casado com Joana Rosa de Jesus, filho do Primeiro Tenente da Marinha João Pinto Rios e da Dona Ana Rosa de Jesus.

Nas matrículas transcritas, a categoria "estado civil" aparece como um das informações eventualmente disponíveis para cada tripulante. Sobre isso, como já mencionado, Rodrigues argumenta que os dados de filiação ou casamento referem-se ao direito desses herdeiros em receber as soldadas devidas em caso de morte do tripulante no exercício profissional. Entretanto, observamos que em algumas matrículas de tripulantes e em certos navios esses dados não constam, o que provavelmente dificultava o acesso a certos direitos. Tal ausência obrigava à feitura 
ISABELLA FERREIRA et al. • "História social dos trabalhadores do mar"

de ações de reconhecimento de parentesco, nos casos em que o marinheiro viesse a falecer no trabalho, distante de casa, obrigando seus familiares a encararem longos e caros processos judiciais para conseguirem receber o pagamento ao qual eles tinham direito, por herança. ${ }^{.1}$

Simultaneamente, enquanto se observava esta questão, a pesquisa revelou pontos interessantes e que possibilitam novas reflexões. Dados parciais apontam que o mar atraía mais os homens solteiros, e que estes eram a maioria dentre os trabalhadores braçais (4I,I5\% ou I,6I vezes mais que os oficiais). Dessa forma, é possível notar que existem diferenças entre os tripulantes dos navios estudados no quesito "estado civil": por exemplo, o número de oficiais casados equivale ao dobro do número de trabalhadores braçais nessa mesma condição.

Outra diferença que salta aos olhos nos dados é que, enquanto a diferença entre os oficiais solteiros e casados é pequena dentro dessa categoria profissional (29,78\% e 28,I8\%, respectivamente), entre os trabalhadores braçais há uma grande diferença em números relativos (41,15\% são solteiros e II,72\% são casados).

Essas percepções nos levaram a buscar na bibliografia algumas respostas. Por exemplo, o fato dos oficiais receberem melhores salários e possuírem melhor status na hierarquia do navio e, portanto, usufruírem de condições financeiras e materiais mais seguras para o sustento de uma família, o que poderia influenciar na decisão de se casar ou não. De acordo com Scott,

refletir sobre os comportamentos demográficos, os sistemas familiares e de herança, a organização do agregado doméstico, nas variadas regiôes de Portugal Continental (Norte, Centro e Sul) e Insular (especialmente os Açores) exige que o pesquisador tenha consciência da extrema diversidade regional e intra-regional que caracterizou o pequeno reino europeu. ${ }^{12}$

Some-se a essa complexidade o caráter específico da profissão desses homens, que demandava ausência constante.

Ainda são poucas as referências bibliográficas sobre o estado civil no âmbito da navegação, mas queremos destacar que tal tema merece um olhar especial, ao revelar questões como a articulação entre vida em terra e vida no mar, quais os vínculos desses marinheiros e como eles estruturavam suas famílias. Podemos pensar também nas questões econômicas e no direito de herança. As possibilidades são diversas e esperamos contribuir para futuras pesquisas. Há especificidades a serem consideradas, como no

II RODRIGUES, J. "Marítimo de profissão: as matrículas de marinheiros e a história marítima de Portugal e seus domínios nos séculos XVIII e XIX”. Almanack, n. 2I, 2019. p. 25.

I2 SCOTT, A. S. V. "Aproximando a metrópole da colônia: família, concubinato e ilegitimidade no noroeste Português (século XVIII e XIX). Anais do XIII Encontro Nacional de Estudos Populacionais, 2002. p. 2. 


\section{REVISTA ANGELUS NOVUS}

caso dos capelães, presenças constantes nos navios mercantes por determinação legal, mas que não foram incluídos em nossa contagem, pois todos eles eram obrigados a adotar o estado de solteiros. Assim, para os capelães, não faria diferença saber se o mar atraia mais solteiros ou casados, ou inseri-los no cômputo das diferenças entre oficiais e não oficiais.

Além do menor número de informações notadas no caso dos tripulantes registrados com menção à cor, como a ausência dos pais, da naturalidade e, às vezes, da idade, separamos os escravos em outro gráfico, pois percebemos que existem diferenças na formação e escolha dos seus nomes devido à sua condição de escravizados. Entre os I22 escravos, 65 possuem apenas um ou dois nomes, mas não sobrenome, ou seja, $53,28 \%$ dos casos; outros 20 escravos (16,39\%) têm um nome ou sobrenome que refere seu senhor: "dar-se-ia às vezes ao escravo o nome do seu proprietário, sobretudo quando este era também seu padrinho de baptismo". ${ }^{\text {i3 }}$ Por outro lado, pode-se associar tal fato à noção de posse, propriedade e domínio: logo, o escravo possui o sobrenome do senhor para mostrar que este tinha poder sobre aquele.

No navio Napoleão Primeiro, havia onze escravos, listados na seguinte ordem: Antônio, Antônio, José, Joaquim, Joaquim, Bento, Domingos, Thomas, Manuel, Manuel e Matheus. Percebemos aqui a pouca importância dada à função denotativa do nome, ou seja, sua função de marcar a individualidade do indivíduo e distingui-lo dos restantes em uma determinada "população de referência”, ${ }^{14}$ pois vários nomes se repetem sob a propriedade de um mesmo senhor. Não se fazia distinção entre alguns escravos, por isso levantamos a possibilidade de que estes deveriam servir da mesma forma e atender ao mesmo chamado. Devemos atentar ao fato de que os dois primeiros escravos da lista possuem o mesmo do seu senhor, também capitão do navio, Antônio Caetano Firme; assim, entre os escravos, eles poderiam possuir funções diferentes e eventualmente ocupar uma posição menos dura, ou o contrário, a depender da índole do senhor.

De forma oposta ao que ocorria com os escravos, muitos capitães de navio tinham nomes mais longos, com até três sobrenomes, como o capitão do navio Lantígua, Manuel Felizardo Carvalho Almeida, ou o do Espirito Santo, José de Oliveira Guedes Travessa. A quantidade de sobrenomes procurava mostrar certa origem nobilizante, status social ou riqueza mais elevada. Desse modo, percebemos a hierarquia social também por meio dos nomes dos indivíduos. 
Por fim, elaboramos outra planilha, destinada aos registros dos I.196 tripulantes que não se encaixavam em nenhum dos casos mencionados anteriormente e que representam $25,76 \%$ do total da amostra. O número elevado demonstra a falta de padronização para a escolha dos nomes e sobrenomes pelos pais para designar os filhos, além de displicência no preenchimento da matrícula por parte dos escrivães da Junta do Comércio lisboeta ou de quem as recebia, quando o preenchimento era feito por um oficial do navio, bem como a ausência de padronização do preenchimento. Encontramos casos do mesmo tripulante que, em viagens diferentes, é registrado somente com o nome do pai, ou com o nome dos ascendentes incompletos, o que dificulta ainda mais o trabalho de um genealogista ou de outro pesquisador em busca de informações sobre a família desses tripulantes. Veja alguns exemplos.

a) Joaquim da Cruz, por duas vezes embarcado no navio Europa como capelão, foi registrado primeiramente como natural de Miranda do Corvo e filho de José da Cruz e Patrícia Maria; outra vez, como natural de Coimbra e filho apenas de José da Cruz;

b) José Francisco de Sá, marinheiro natural de Lisboa, embarcou duas vezes no Harmonia, sendo registrado como filho de Felizarda dos Reis e Manuel Francisco ou Manuel Francisco de Sá;

c) Bernardo José da Silva, portuense sem indicação de função, aparece em das matrículas do Pensamento Ligeiro como filho de Maria Rosa e Antônio José ou Antônio José da Silva.

Estudar a escolha e a transmissão dos nomes é muitas vezes deparar-se com um "mundo de referencialidades submersas" is ligadas ao gosto: "escolhi esse nome para o meu filho porque é um nome de que eu gosto" ou "porque é muito bonito" ${ }_{16}$

Ao longo da análise, notamos a ausência de padronização. Apesar da maioria dos registros fazer referência ao nome ou sobrenome do pai, essa não era uma regra estrita. Os nomes escolhidos possuíam abrangência de possibilidades de escrita; sendo assim, entre as classes populares, principalmente, as práticas dominantes se caracterizavam pela diversidade. ${ }^{17}$ Ademais, algumas informações não estavam presentes e, portanto, dificultam análises mais aprofundadas. No entanto, é interessante notar que se tratou de um período de inúmeras possibilidades quanto aos sobrenomes que pessoas casadas adotariam e quais patronímicos transmitiriam aos seus descendentes. Além disso,

I5 PINA-CABRAL, J. “Outros nomes, histórias cruzadas: apresentando o debate”. Etnográfica, v. I2, n. I, 2008. p. II.

I6 Ibidem, p. II.

I7 MONTEIRO, N. G. “Os nomes de família em Portugal: uma breve perspectiva histórica”. Etnográfica, v. I2, n. I, 2008. p. 54 . 


\section{REVISTA ANGELUS NOVUS}

percebe-se que, através do estudo dos nomes das pessoas de forma seriada, pode-se entender a dimensão social na qual os indivíduos portadores desses nomes estão inseridos.

Diante das condições de cor, familiares e outras formas de distinção social, optamos por investigar preliminarmente a possibilidade de ascensão profissional no mundo do trabalho marítimo. A princípio, ressaltamos a limitação de lidar com a questão em um período de tempo curto (I807-I808). Nesse intervalo, não é possível afirmar como e quais eram as possibilidades de ascensão. Outra dificuldade foi organizar os dados dos tripulantes. Por conta da caligrafia e do descuido dos escreventes com relação a algumas informações, é difícil afirmar com certeza quais foram os navegantes que realizaram múltiplas viagens, principalmente entre marinheiros e outros servidores com funções braçais, para os quais a falta de registros completos era mais comum.

Após a coleta e separação dos dados, foram observados 57 oficiais, 86 trabalhadores braçais e 8 homens sem registro de função que realizaram mais de uma viagem. Baseamos nossa análise nesses dados. Observamos que a ascensão profissional poderia ser uma realidade, especialmente entre os que ocupavam posições mais altas na hierarquia do navio. Um exemplo claro está nos pilotos que, posteriormente, exerceram o cargo de capitão. Havia também homens mais jovens no cargo de praticantes de piloto, que pela lógica seriam futuros pilotos. É possível perceber que, em geral, os homens nessa posição possuíam algum grau de parentesco com os pilotos ou capitães do navio.

Alguns cargos aparentemente estavam relacionados à idade do tripulante, como moģos ou mancebos, por exemplo. Observamos também alguns casos de descenso profissional, do cargo de marinheiro para o de moço ou mancebo, sendo estes casos mais raros.

Os ofícios mecânicos ou outros serviços especializados não apresentaram nenhum tipo de variação na amostragem: calafates, despenseiros, carpinteiros, capelães, cirurgiões e escrivães eram funções que exigiam um conhecimento peculiar, portanto era esperado que não houvesse mudanças.

Por fim, com o intuito de compreender o impacto do quesito "idade" para a inserção dos homens no mundo do trabalho marítimo do período, refletimos sobre o conceito de infância no começo do século XVIII e a relação dessa faixa etária com as funções presentes nos navios.

Dentre o total de registros da amostragem, construímos um gráfico que abarcava apenas aqueles que tivessem de o e i8 anos de idade, uma vez que ainda não havíamos estabelecido qual seria a idade que corresponderia à infância nessa época. Assim, de

I6 • ano XII, n. I7, 202I • ISSN 2I79-5487 
4.253 pessoas, I.587 haviam se iniciado no trabalho marítimo até os dezoito anos. $\mathrm{Na}$ seleção, foram somados também os trabalhadores para os quais, ao subtrair a idade do tempo de trabalho no ato da matrícula, o resultado fosse uma idade menor ou igual a dezoito anos. Separamos o gráfico em agrupamentos de anos: dos o aos 6 anos; dos 7 aos 8; dos 9 aos IO; dos II aos I2; dos 13 aos I4; dos I5 aos I6 e dos I7 aos I8. O maior grupo é aquele que corresponde à faixa etária entre 17 e I8 anos: $35,5 \%$ do total de pessoas. A menor idade registrada foi a 4 anos. É possível visualizar os dados no gráfico a seguir.

Gráfico 3 Tripulantes por faixa etária até os I8 anos (I807-1808)

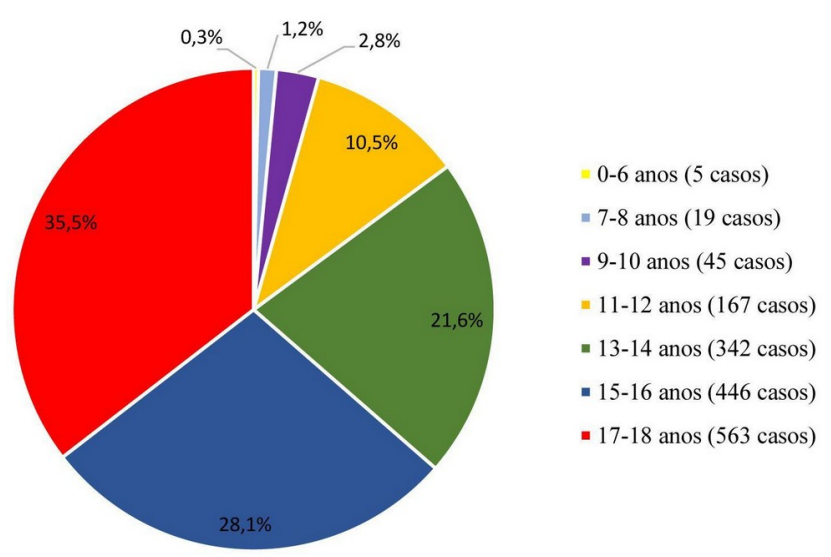

Fonte Arquivos Nacionais/Torre do Tombo, Junta do Comércio, maço 35, ordem 65, caixa II8 transcrito em RODRIGUES, J. et al. "Matrículas de tripulações mercantes em Portugal em 1807-1808 como fontes para o trabalho do historiador". Revista de Fontes, v. 7, n. I2, p. I79-455, 2020.

Posteriormente, separamos esses trabalhadores até i8 anos de acordo com suas funções. Primeiramente, havia dois grandes grupos que abarcavam funções braçais e oficiais e, dentro dessa divisão, os segmentos das funções braçais (marinheiro e mancebo; moço e servente; cozinheiro) e os segmentos das funções oficiais (piloto, mestre, contramestre, praticante, capitão, escriturário, despenseiro, calafate, aulista, condestável, papeiro, sobrecarga, carpinteiro e cirurgião), como mostram os gráficos a seguir. 
Gráfico 4 Funções braçais exercidas até os I8 anos na marinha mercante (I807-I808)

Funções Braçais

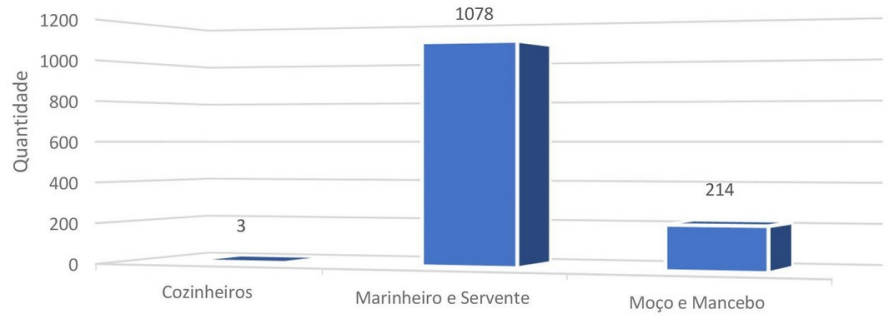

Fonte Arquivos Nacionais/Torre do Tombo, Junta do Comércio, maço 35, ordem 65, caixa II8 transcrito em RODRIGUES, J. et al. "Matrículas de tripulações mercantes em Portugal em 1807-1808 como fontes para o trabalho do historiador". Revista de Fontes, v. 7, n. I2, p. 179-455, 2020.

Gráfico 5 Cargos exercidos até os I8 anos na marinha mercante (I807-I808)

Funções Oficiais

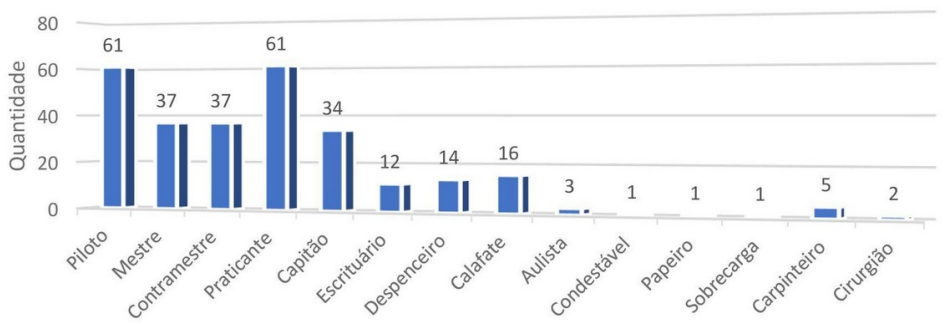

Fonte Arquivos Nacionais/Torre do Tombo, Junta do Comércio, maço 35, ordem 65, caixa II 8 transcrito em RODRIGUES, J. et al. "Matrículas de tripulações mercantes em Portugal em I807-1808 como fontes para o trabalho do historiador". Revista de Fontes, v. 7, n. I2, p. I79-455, 2020.

Como é possível visualizar nos gráficos, a maioria dos tripulantes até os I8 anos exerciam funções braçais e, dentre estas, grande parte era de marinheiros e serventes, totalizando I.295 trabalhadores. Ambas foram colocadas no mesmo segmento de função braçal, uma vez que a designação "marinheiro" era mais comum no século XIX e "servente" no século XVIII, embora correspondesse ao mesmo escopo profissional.

Outra parte daqueles incluídos em tais funções eram os moços e mancebos, os quais eram numericamente inferiores aos marinheiros e serventes, ainda que realizassem tarefas semelhantes. É importante observar que, em algumas matrículas, havia aqueles trabalhadores sinalizados ao mesmo tempo como marinheiros, moços e mancebos, e esses foram contabilizados como marinheiros.

I8 • ano XII, n. I7, 202I • ISSN 2I79-5487 
Por fim, havia uma minoria de cozinheiros, o que não quer dizer que existiam tão poucos cozinheiros entre as tripulações, mas sim que foram poucos os que começaram a trabalhar jovens. Tais pessoas poderiam ascender socialmente porque não eram negros, fator que se tornava uma espécie de barreira invisível para a mobilidade profissional ascendente, mas que a tabulação dos dados seriais permite deixa ver.

O Gráfico 5 sistematiza todas as funções que não eram braçais, mas sim de oficiais, aquelas de maior prestígio e melhor remuneradas. A maioria é composta pelos cargos de capitão, piloto, praticante (isto é, aqueles que viriam a ser pilotos), mestre e contramestre. Eram homens que adentravam cedo nessas profissóes vistas como mais importantes, o que pode significar que se tratava de jovens com uma condição social mais elevada em terra e que tinham a possibilidade de ascender nos cargos marítimos, diferentemente dos trabalhadores braçais. Por exemplo, foram identificadas pessoas que se iniciaram aos 13 ou I4 anos nos cargos de praticantes, enquanto outras nessa mesma idade já eram pilotos, o que indica que haviam sido praticantes ainda mais novos.

Há outro grupo de tripulantes que merece destaque: o dos pretos. Do total assinalado para a faixa etária estabelecida, foram encontrados 43 deles com idade atribuída, ou seja, existiam mais pretos nos navios, mas geralmente eles não tiveram suas informaçôes registradas nas matrículas como os demais tripulantes, entre elas a idade. A maioria dos registros que informam a idade dos pretos até os I8 anos os incluíram na faixa etária entre II e I4 anos. Percebemos que a maioria dos que não tinham função designada eram pretos e escravos. É possível encontrá-los em funções braçais como a de marinheiro, mas nunca em cargos de oficiais. Por fim, é importante mencionar que a maioria dos escravos dos quais sabemos a idade e não tinham função situavam-se na faixa entre 5 a II anos, tendo apenas dois deles 18 anos. Isso mostra uma entrada muito precoce no mundo do trabalho em razão da cor.

Em Portugal, dois tipos de documentação diferenciavam as idades da vida: a eclesiástica e a laica. A primeira definia a infância até os 7 anos, com a alegação de que, com essa idade, o ser humano já adquirira malícia e razão. De acordo com Isabel Sá, em fontes eclesiásticas como os manuais de confissão, após os I2 e I4 anos as "raparigas e os rapazes” já poderiam ter vontade própria. Assim, a infância nesse tipo de fonte poderia se prolongar até os 14 anos. As pessoas que tinham entre I4 e 25 anos já eram considerados “moços”, ou seja, tinham o estatuto de adolescente ${ }^{18}$. Já a documentação 


\section{REVISTA ANGELUS NOVUS}

laica definia a infância até I2 ou I4 anos, período em que já adquiriram maturidade sexual e reprodutiva e responsabilidade penal ${ }^{19}$.

Além dessas fontes, recorremos ao Dicionário de Bluteau. Segundo as definições das idades contidas nele, a infância ia do início da vida até o momento em que o indivíduo era capaz de usar a razão, no caso aos sete anos, mas ele recorria a outros autores para os quais esse período da vida poderia se estender até os quatorze anos. Contudo, Bluteau definia como outro período as idades de nove e dez anos: a puerícia, uma divisão na infância. O Dicionário estabelecia ainda que a adolescência começava aos quinze anos, mas também referia outras opiniões que estendiam a adolescência até os 25 ou 30 anos. Para ele, a adolescência estaria entre os quinze e os 25 , alegando que era nessa idade que os rapazes deixavam de crescer (as meninas amadurecem antes, na sua concepção, aos $2 \mathrm{I}$ anos) ${ }^{20}$.

As fontes portuguesas comprovam que os limites da infância eram caracterizados pela fluidez, existindo fronteiras cívicas, jurídicas e religiosas, o que dificulta definições mais exatas. Junto a essas fronteiras, também deve ser levada em consideração a questão social: para muitas crianças, o início da vida adulta começava entre os doze e os quatorze anos - logo, em plena adolescência ${ }^{21}$. Nas listas de matrículas de tripulantes, é possível vislumbrar muitos jovens nessas idades que já haviam adentrado o mundo do trabalho: eles correspondem a 32,1\% da amostragem. De acordo com Vailati, aos 7 anos a criança já poderia trabalhar, dependendo da sua classe social, principalmente se era escrava ou exposta ${ }^{22}$.

Esses tópicos, entre muitos outros, só puderam ser elencados a partir da transcrição. A busca por respostas a essas e outras indagações pressupõe a própria transcrição e sistematização dos dados. Eles exemplificam a importância da tarefa de transcrever documentos e, com isso, construir bancos de dados colaborativos para subsidiar pesquisas futuras. Nossa intenção, partindo das premissas da história social, é ir em busca dos homens comuns e do papel desempenhado por eles nos processos históricos - neste caso, no funcionamento eficaz da navegação marítima de longo curso.

VAILATI, L. L. A morte menina: infância e morte infantil no Brasil dos oitocentos (Rio de Janeiro e São Paulo). São Paulo: Alameda, 20 o.

20 BLUTEAU, R. Vocabulario portuguez ES latino: aulico, anatomico, architectonico... (8 v.). Coimbra: Collegio das Artes da Companhia de Jesus, I7I2-I728.

2I SÁ, I. dos G. "As crianças e as idades da vida”. MONTEIRO, N. G. (Org.). História da vida privada em Portugal: a Idade Moderna. Lisboa: Círculo de Leitores, 20II. p. 92.

22 VAILATI, L. L. op. cit.

$20 \cdot$ ano XII, n. I7, 202I $\bullet$ ISSN 2I79-5487 